\title{
OS GRAUS DE AMBIGUIDADE E CONFLITO DE UMA POLÍTICA EDUCACIONAL NA PERSPECTIVA DOS AGENTES DE LINHA DE FRENTE: O CASO DO SAERJ ${ }^{1}$
}

http://dx.doi.org/10.5902/2318133842425

\author{
Diego Mota² \\ Maria Océlia Mota ${ }^{3}$
}

\begin{abstract}
Resumo
Neste texto aborda-se a política de avaliação de desempenho das escolas do Estado do Rio de Janeiro, levada a efeito no âmbito do Sistema de Avaliação da Educação do Estado do Rio de Janeiro - Saerj - no período de 2008 a 2016, com o objetivo de conhecer o processo de implantação segundo os professores. Para isso analisou-se o sistema de avaliação utilizado pela Secretaria de Educação sob a perspectiva das agências burocráticas e do modelo analítico de Matland (1995). Os resultados indicam que o grau de conflito relacionado aos instrumentos de ação colaboraram significativamente para que sua implantação se aproximasse de uma perspectiva política. Os meios de regulação da política tiveram efeitos indutores negativos, de acordo com os agentes envolvidos. Essa condição foi uma das reivindicações manifestas na pauta da greve dos professores em 2016, contribuindo para a descontinuidade da política educacional.

Palavras-chave: políticas educacionais; avaliação em larga escala; avaliação da educação.
\end{abstract}

\section{THE DEGREES OF AMBIGUITY AND CONFLICT OF AN EDUCATIONAL POLICY IN THE PERSPECTIVE OF FRONTLINE AGENTS: THE CASE OF THE SAERJ}

\begin{abstract}
This paper focuses on the educational policy adopted by the state of Rio de Janeiro in the period 2008-2016. The objective of the study is to know its implementation process according to the teachers. For this, we analyzed the assessments system used by the Secretaria de Educação from the perspective of bureaucratic agencies and Matland's analytical model. The research results indicate that the high degree of conflict related to the instruments of action contributed significantly to bring their implementation closer to a political perspective. The means of policy regulation had negative inductive effects, according to the implementing agents. This condition was one of the demands manifested in the teachers strike agenda, contributing to the discontinuity of educational policy.
\end{abstract}

Key-words: educational policies; large-scale evaluation; education assessment.

\footnotetext{
1 O presente trabalho foi realizado com apoio da Capes.

2 Colégio Pedro II, Brasil. E-mail: diegoomota@gmail.com.

3 Pontifícia Universidade Católica do Rio de Janeiro, Brasil. E-mail: oceliamota@gmail.com. 


\section{Introdução}

A Constituição de 1988 abriu um novo paradigma quanto aos direitos fundamentais dos brasileiros, de modo a ser necessário garantir uma educação de qualidade para todos. Assim, a criação do Sistema de Avaliação da Educação Básica - Saeb - influenciou muitos Estados e municípios a desenvolverem parâmetros para acompanhar suas redes de ensino. Com isso as avaliações de monitoramento se enraizaram no cenário educacional brasileiro com o propósito de orientar as decisões em busca de melhorias nos indicadores educacionais (Bonamino; Sousa, 2012).

Convergindo nesse sentido o Estado do Rio de Janeiro implementou o Programa Nova Escola, quando sua rede revelava uma das mais baixas proficiências entre os Estados da federação (Brooke, 2006). Em 2008, o Nova Escola foi substituído pelo Sistema de Avaliação da Educação do Estado do Rio de Janeiro - Saerj -, com a intenção de aprimorar as métricas longitudinais de monitoramento.

Os programas convergiam em relação ao gerenciamento da gestão escolar, na busca de melhorias dos indicadores de eficiência, nas avaliações anuais em larga escala e na bonificação dos servidores em função do desempenho das escolas. Além disso, embora englobasse inicialmente Matemática e Língua Portuguesa, o Saerj "ampliou o número de disciplinas contempladas nas avaliações da rede" (Rio de Janeiro, 2011, p. 1).

A estrutura do Saerj foi desenhada para se aproximar de outras avaliações em larga escala, como o Saeb e o Programa Internacional de Avaliação de Estudantes - Pisa. Todavia, a avaliação era apenas uma das estratégias propostas pela Secretaria de Estado de Educação do Rio de Janeiro - Seeduc - para promover avanços na qualidade da rede. Uma das principais metas estabelecidas pelo novo programa era "estar entre as cinco primeiras posições no ranking de educação nacional até 2014" (Rio de Janeiro, 20112).

O foco nos resultados tornou-se a política oficial da educação estadual e uma das chaves principais para chegar a esse objetivo foi a adoção de um currículo básico obrigatório em toda a rede de ensino. Esse currículo contemplou, gradualmente, todas as disciplinas do ensino fundamental e médio da rede. Nesse cenário, entre 2009 e 2014, a educação pública estadual saiu das últimas posições entre as redes estaduais para a sétima melhor avaliada do país, de acordo com Ideb, para o nono ano do ensino fundamental (Brasil, 2014).

No entanto, alguns autores analisam tais resultados com cautela e criticidade, despertando a atenção para a aproximação feita entre os conceitos de qualidade e desempenho nos indicadores educacionais (Machado; Alvarse; Arcas, 2015). Na visão de Sousa (2014), esses programas "dão ampla visibilidade aos resultados das avaliações", além de "responsabilizar as escolas por esses quocientes através de incentivos simbólicos ou monetários" (p. 412). A autora também enfatiza que essas estratégias para alcançar bons resultados nas avaliações em larga escala podem fornecer concepções questionáveis de uma educação de qualidade. 
Apesar dos tímidos avanços nos indicadores do Saeb entre 2007 e 2015, os diagnósticos da rede estadual do Rio de Janeiro estavam aquém das metas propostas pelo Saeb. Além disso, as comparações com outras redes estaduais, feitas nas mídias da Seeduc, desconsideravam o precário cenário da educação pública nacional.

O ciclo dessa política de avaliação e monitoramento ocorreu entre 2008 e 2016. As séries finais do ensino fundamental e todo o ensino médio realizavam três avaliações bimestrais - Saerjinho - e o Saerj no fim do ano. A avaliação em larga escala era baseada nos descritores do currículo básico, um dos principais instrumentos utilizados em sua implantação. Para fomentar seu empreendimento educacional a Seeduc estabeleceu metas de desempenho para cada escola e potenciava essa intenção com bonificação salarial para os professores e premiações para os estudantes.

Contudo, a insatisfação com essa política educacional foi uma das principais manifestações da greve realizada pelos docentes em 2016. As reivindicações deste movimento, associadas à grave crise financeira enfrentada pelo Estado, levou a Seeduc a encerrar o ciclo da política de avaliação. Diante do contexto descrito, destacamos a possibilidade de discutirmos sobre um momento específico da profissão docente, no qual os instrumentos de ação pública são questionados pelos agentes de linha de frente, que dão vida à política em implementação.

Considerando todos esses aspectos, destaca-se as percepções dos agentes implementadores acerca desta política educacional, tendo como base seus posicionamentos. Um caminho promissor, nesse sentido, é analisar seus discursos sob uma perspctiva crítica e exploratória, tendo como base os referenciais de Matland (1995) e das agências burocráticas de Lipsky (1980).

\section{Fundamentação teórica}

O campo de análise da implementação de políticas ganhou espaço no cenário nacional com a ampliação da literatura que aborda os ciclos de políticas. Nesse contexto, as pesquisas baseadas em modelos top down e bottom up originaram uma geração de síntese dos modelos analíticos, com uma nova perspectiva dos estudos sobre implementação no início dos anos 1990.

Considerando os cenários de implementação, os atores e as teias de relações que permeiam seus processos, uma política pode ser analisada em suas diversas fases, as quais se desenvolvem simultânea e sincronicamente. Nesse sentido, são muitas as possibilidades de análise das políticas públicas, seja no contexto da agenda, das decisões políticas, passando por sua implantação, avaliação ou reformulação. É nesse espaço que os projetos dos governos se desenvolvem sob a perspectiva daqueles que interagem com os usuários. Em síntese, é nessa fase que os objetivos do governo ganham vida a partir de suas intenções, sendo uma das chaves mais influentes para que seus resultados sejam alcançados. Por esse motivo, a compreensão desse contexto de implementação é fundamental para conhecer como as políticas vão sendo ressignificadas ao longo de seu desdobramento (Hill; Hupe, 2003).

Uma das lentes analíticas que utilizaremos nesta investigação é a perspectiva das agências burocráticas, proposta por Michel Lipsky em 1980. Segundo o autor a ação dos agentes implementadores tem papel determinante nos resultados das políticas públicas, pois são eles que concretizam suas intenções e estão em contato direto com os cidadãos. 
Esses agentes de linha de frente são por ele denominados burocratas do nível da rua. Segundo Lipsky (1980) os atores não são apenas executores das decisões propostas. Por terem algum grau de autonomia ao tomar decisões no exercício de suas funções, esses burocratas possuem discricionariedade na implementação da política. Nesse sentido, na interação entre tais agentes e a população, a política é adaptada às condições do contexto. Eles não entregam as políticas idealizadas, simplesmente. Seus objetivos são ressignificados por meio da interpretação das regras e da complexidade do campo de atuação.

Os burocratas de nível de rua possuem um grande poder no desenvolvimento de uma política, considerando-se sua discricionariedade (Lotta, 2012). Segundo Lotta (2010) a discricionariedade dos agentes de linha de frente é resultante "da interação que exercem entre seus próprios valores, os valores de outros atores envolvidos, dos procedimentos, restrições, estruturas, incentivos, encorajamentos e proibições" (p. 4). Portanto, prestar atenção para o papel dos burocratas de nível de rua no processo de implantação de uma política é uma via perspicaz para descrever sua dinâmica e compreender seu desenvolvimento na linha de frente.

Os autores que se dedicam ao campo de implementação buscam conhecer os fatores que influenciam os bons resultados de uma política e suas limitações. Nesse caso, a compreensão das variáveis presentes no contexto de seu desenvolvimento são a questão central de análise. O modelo analítico de Matland (1995) apresennta uma perspectiva pertinente para descrevermos a política de avaliação da rede estadual de ensino do Estado do Rio de Janeiro, pois o autor assume que o grau de discricionariedade dos agentes implementadores e a forma como a política se desenvolverá estão relacionados às características de seu desenho na elaboração.

Matland (1995) descreve que as políticas apresentam certo grau de conflito e ambiguidade, em todos os seus aspectos. A ambiguidade de uma política pode estar relacionada aos fins ou meios, sendo uma fonte potencial de aprendizado. Para o autor políticas bem definidas não geram dúvidas nem margem de interpretação; políticas genéricas geram, esse é o grau de ambiguidade.

O grau de conflito de uma política é diretamente proporcional a quanto os atores discordam sobre o que deve ser feito e como deve ser feito. Entretanto, conflito e ambiguidade podem aparecer em maior ou menor intensidade. Essa variáveis influenciam a forma de atuação dos sujeitos envolvidos na implementação. Diante de leis e descritores confusos ou contraditórios os atores se comportam de maneira mais ou menos distante daquilo que foi esperado. O modelo de Matland (1995) apresenta tendências de construção de contextos onde os atores irão agir, no sentido de considerar o quanto os agentes concordam ou discordam em relação aos fins ou aos meios de uma política pública.

Além disso, a literatura considera essas duas variáveis manipuláveis gerencialmente. Podem ser intencionais e propositais para que uma política funcione. Também podem se transformar ao longo do tempo. Considerando esses fatores, uma política pode estar mais próxima de uma das quatro perspectivas propostas pelo autor, de acordo com a figura 1. 
Figura 1 -

Matriz de ambiguidade e conflito e as aproximações dos modelos de implantação de uma política.

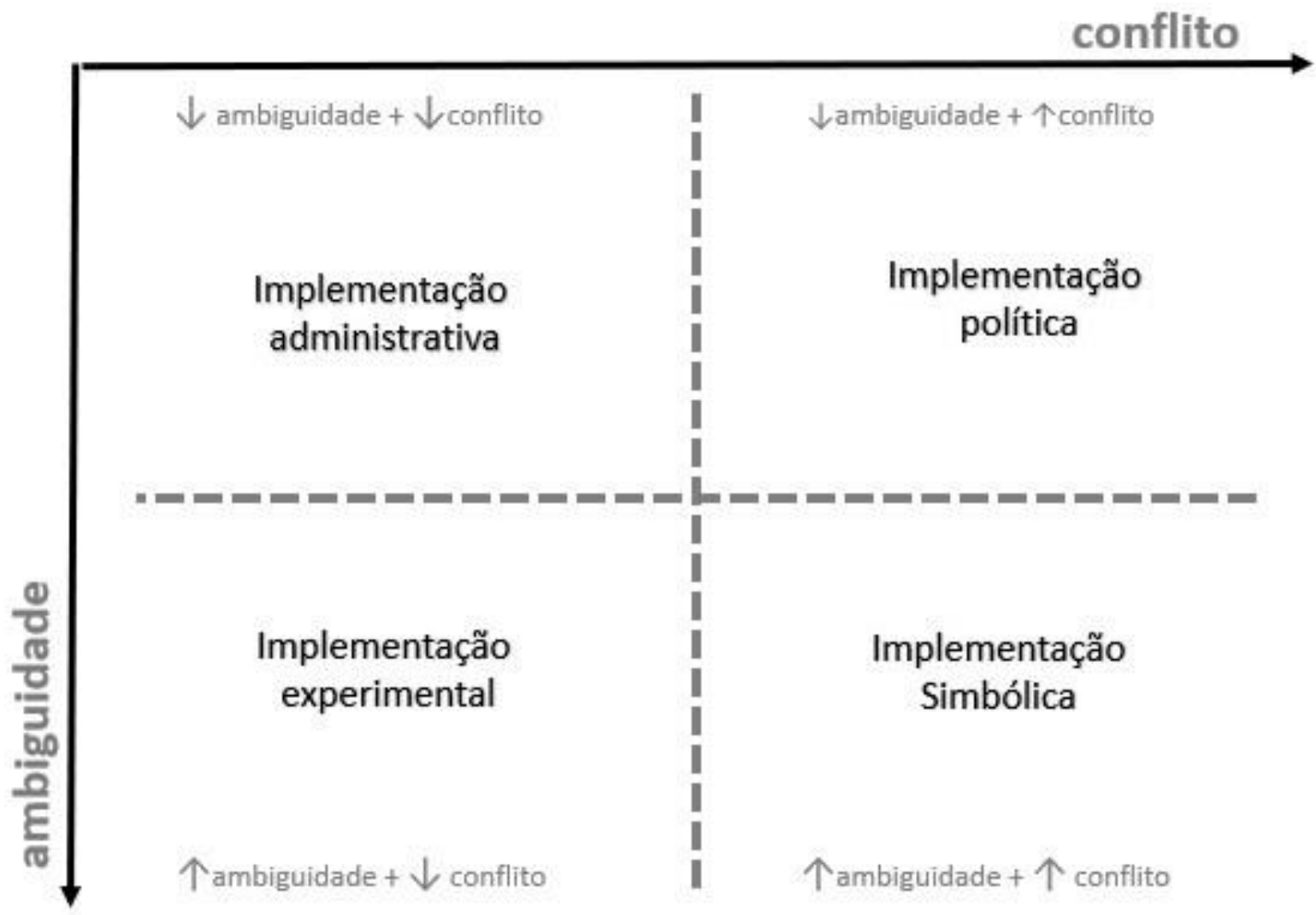

Fonte: Matland, 1995.

A perspectiva apresentada por Matland (1995) permite mapear como a política se desenvolve para pensarmos em tendências, já que uma política pode circular entre os quadrantes de acordo com os ajustes e seu contexto. Um processo de implementação pode se aproximar de uma perspectiva administrativa, quadrante superior esquerdo da figura 1, quando os graus de ambiguidade e conflito são baixos. Nesse contexto, a ações são previsíveis e predeterminadas, logo os recursos investidos determinam resultados.

As políticas que apresentam ampla margem de interpretação - muita ambiguidade e pouca discordância entre os seus diversos atores - baixo conflito - convergem para uma perspectiva experimental, quadrante inferior esquerdo da figura 1. Nesse cenário de implementação o contexto determina o processo. Assim, o grau de ambiguidade de uma política pode ser proposital, permitindo que os agentes interpretem e adaptem os objetivos a seus contextos. Essa margem de interpretação também pode ser uma estratégia de experimentação e aprendizado, mas pode ter o objetivo de minimizar os conflitos entre os atores. A literatura, no entanto, também entende as margens de ambiguidade como possíveis erros, pois seus objetivos podem ser desviados do foco inicial.

Quando os objetivos de uma política são claros - pouca ambiguidade - e o nível de conflito sobre os meios ou fins entre os atores é acentuado, a implementação se aproxima de uma perspectiva política, quadrante superior direito da figura 1. São casos nos quais 
os governantes desejam pôr em ação uma política marcada por resistências dos atores: a diminuição da ambiguidade e a distribuição de recursos podem influenciar seus resultados.

A implementação simbólica aparece em contextos marcados por acentuada ambiguidade e alto grau de conflito em seu desenho - ver quadrante inferior direito da figura 1. Nessas situações os atores não concordam com a política e têm dificuldades em sua interpretação. Dependendo de sua evolução os instrumentos de ação pública podem ajudar a diminuir os graus de conflito e ambiguidade, fazendo-a se deslocar para outros quadrantes. São temas muitas vezes polêmicos e que envolvem interesses de múltiplas camadas, níveis e atores, como o caso das políticas de aborto. Neles, os resultados são desenvolvidos lentamente pela complexidade dos temas.

Baseando-se nas variáveis apresentadas pela literatura de implantação de políticas públicas, o objetivo do artigo é analisar a implementação da política educacional da rede pública estadual do Rio de Janeiro desenvolvida no período de 2008 a 2016, no contexto dos burocratas de nível de rua. De acordo com o referencial teórico as escolhas e ações dos agentes de linha de frente influenciam significativamente o desenvolvimento desse projeto educacional, garantindo ou não sua efetivação.

Considerando a complexidade das políticas educacionais e os fatores que atuam ao mesmo tempo nesse processo, os agentes de linha de frente são uma variável considerável para compreendermos os rumos de uma política. Por todos esses aspectos analisar essa política educacional sob a ótica dos professores pode ser um caminho promissor para entender as questões positivas e os fatores que limitaram as possibilidades de sua implementação.

\section{Os participantes da pesquisa}

Com o objetivo de conhecer as perspectivas discursivas dos atores envolvidos na implantação da política de avaliação da rede estadual do Rio de Janeiro, utilizamos como recorte amostral um grupo social de quinze professores. Todos são docentes ativos do nono ano do ensino fundamental, uma das séries avaliadas pelo Saerj.

Nesse recorte, incluímos dez escolas da Baixada Fluminense - Metro V -, região metropolitana da capital, de modo que a escolha do campo está relacionada aos baixos desempenhos dos alunos de nono ano, segundo os indicadores educacionais. A região metropolitana possui uma população numerosa e carente de serviços básicos. De acordo com o Ideb 2015 todos os municípios da região apresentaram proficiência abaixo da média do Estado nas séries finais do ensino fundamental. Na última versão do Saerj, cujos indicadores são espelhados na Prova Brasil, as escolas da Metro V tiveram um desempenho baixo em Língua Portuguesa e inadequado em Matemática para as turmas de nono ano (Rio de Janeiro, 2016).

O grupo de professores é composto por três homens e doze mulheres com idade média de 40 anos: desvio padrão 7.15. Dentre eles oito são especialistas, dois são mestres e um é doutor. Esses docentes dedicam 20 horas de sua atividade profissional à rede estadual, na qual $95 \%$ são efetivos há mais de quatro anos; $50 \%$ dos participantes também são professores de outras redes de ensino e $80 \%$ exercem o ofício há mais de dez anos. 


\section{As representações sociais e o discurso do sujeito coletivo}

O paradigma das representações sociais proposto por Moscovici (1961) é uma perspectiva teórica que investiga a construção do mundo e seus sentidos para os sujeitos que formam os grupos sociais. Além de ser um campo teórico da psicologia social as representações sociais são fenômenos produzidos no cotidiano que normatizam o comportamento dos indivíduos.

Segundo Moscovici (2007), são um "conjuntos de conhecimentos socialmente construídos e partilhados, com os quais e através dos quais nós pensamos, falamos, decidimos o que fazer, nos apropriamos do mundo e Ihe damos sentido" (p. 56). Elas também apresentam diversas camadas, envolvendo questões identitárias e discursivas partilhadas pelos sujeitos de um grupo social. Além disso, seus conteúdos revelam elementos que traduzem concordâncias entre os sujeitos, seus significantes partilhados, suas divergências e suas particularidades.

Analisar as representações discursivas dos agentes de linha de frente da política do Saerj é uma possibilidade de captar as opiniões, crenças e posições dos sujeitos sobre um objeto que faz parte da sua vida cotidiana. Nesse sentido, o discurso do sujeito coletivo - dsc - é uma via metodológica com amplo potencial analítico nas pesquisas sobre representações sociais (Lefèvre; Lefèvre, 2006).

Esta técnica possibilita mapearmos os discursos socialmente construídos e compartilhados entre os sujeitos de um grupo social (Lefèvre; Lefèvre, 2014). Sua elaboração envolve diversas etapas, tendo como foco a identificação das ideias centrais presentes na fala dos sujeitos. Cada ideia central é organizada a partir das expressõeschave que a fundamentam. Dessa forma, podemos evidenciar os elementos representacionais, com maior grau de compartilhamento, relacionados a cada núcleo de sentido.

Figura 2 -

Representação da construção do DSC a partir da identificação das expressões chave presentes nos depoimentos dos sujeitos de um grupo social acerca de uma mesma ideia central.
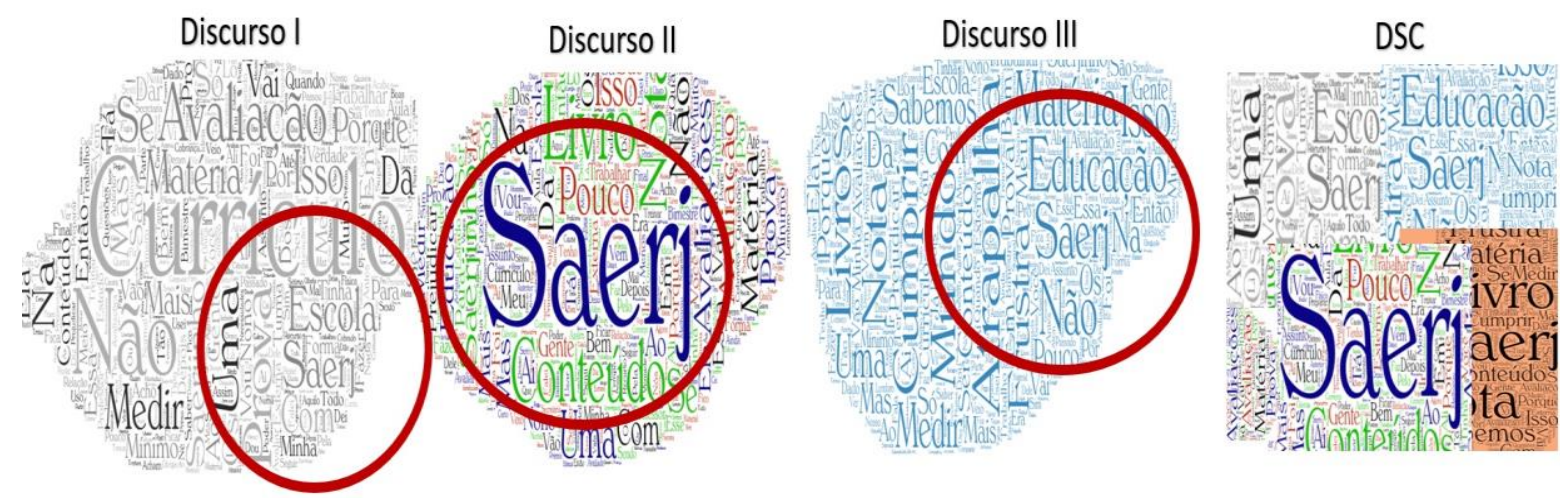

Fonte: autores. 
Essa metodologia permite ao pesquisador explorar as percepções dos sujeitos e organizar seus significados em um plano gráfico. Muito mais que um conteúdo a linguagem verbal é uma das faces do habitus, considerada como um código comum de cada grupo social (Bordieu, 1994). Sendo assim, a linguagem expressa as posições aceitáveis dentro do campo no qual os indivíduos estão inseridos, uma face que revela traços e marcadores das representações sociais do grupo.

Por esse motivo, a articulação das representações discursivas com o papel dos agentes de linha de frente na implementação de uma política nos oferece, para esta análise, a visão de uma "coletividade falando", dando lugar a um acréscimo da densidade semântica nas representações sociais, fazendo com que a ideia ou posicionamento dos depoentes apareça de modo "encorpado", desenvolvido, enriquecido, desdobrado na forma de um discurso único redigido na primeira pessoa do singular (Lefèvre et al., 2009, p. 2)

\section{A produção dos dados}

Os depoimentos foram obtidos por meio de entrevistas abertas realizadas entre os meses de fevereiro e março de 2016. Seguimos os protocolos éticos que envolvem pesquisas com seres humanos. Todos os professores entrevistados assinaram o termo de consentimento livre e esclarecido antes da obtenção de suas declarações e foram informados a respeito dos objetivos deste estudo. A pesquisa foi aprovada pelo Comitê de Ética da Universidade Federal do Rio de Janeiro e pela Seeduc. A questão indutora foi 'fale sobre o Saerj', com o objetivo permitir ao participante desenvolver livremente o tema abordado, de acordo com a metodologia proposta para entrevistas abertas (Flick, 2008).

A categorização do corpus textual foi realizada com o auxílio do software Iramuteq na forma de classificação hierárquica descendente (Reinert, 1987). A partir dessa análise foram identificados os segmentos de texto que apresentam maior aproximação de vocabulários e sentidos, possibilitando sua contextualização, de acordo com a classe detectada. Os resultados são organizados em um dendograma, com grande potencial contributivo nos estudos de representações sociais, pois estas categorias podem indicar conhecimentos compartilhados sobre um dado objeto e os diferentes aspectos de uma representação (Camargo; Justo, 2013).

Os resultados da análise realizada com o auxílio do software são apresentados no dendograma da figura 3. Cada classe de palavras reúne elementos com maior proximidade lexical e de contexto semântico. O programa também identifica os sujeitos e organiza os segmentos de texto referenciais para a construção das ideias centrais de cada discurso do sujeito coletivo. 
Figura 3 -

Dendograma da classificação hierárquica descendente acerca do Saerj na perspectiva dos professores participantes da pesquisa ${ }^{4}$.

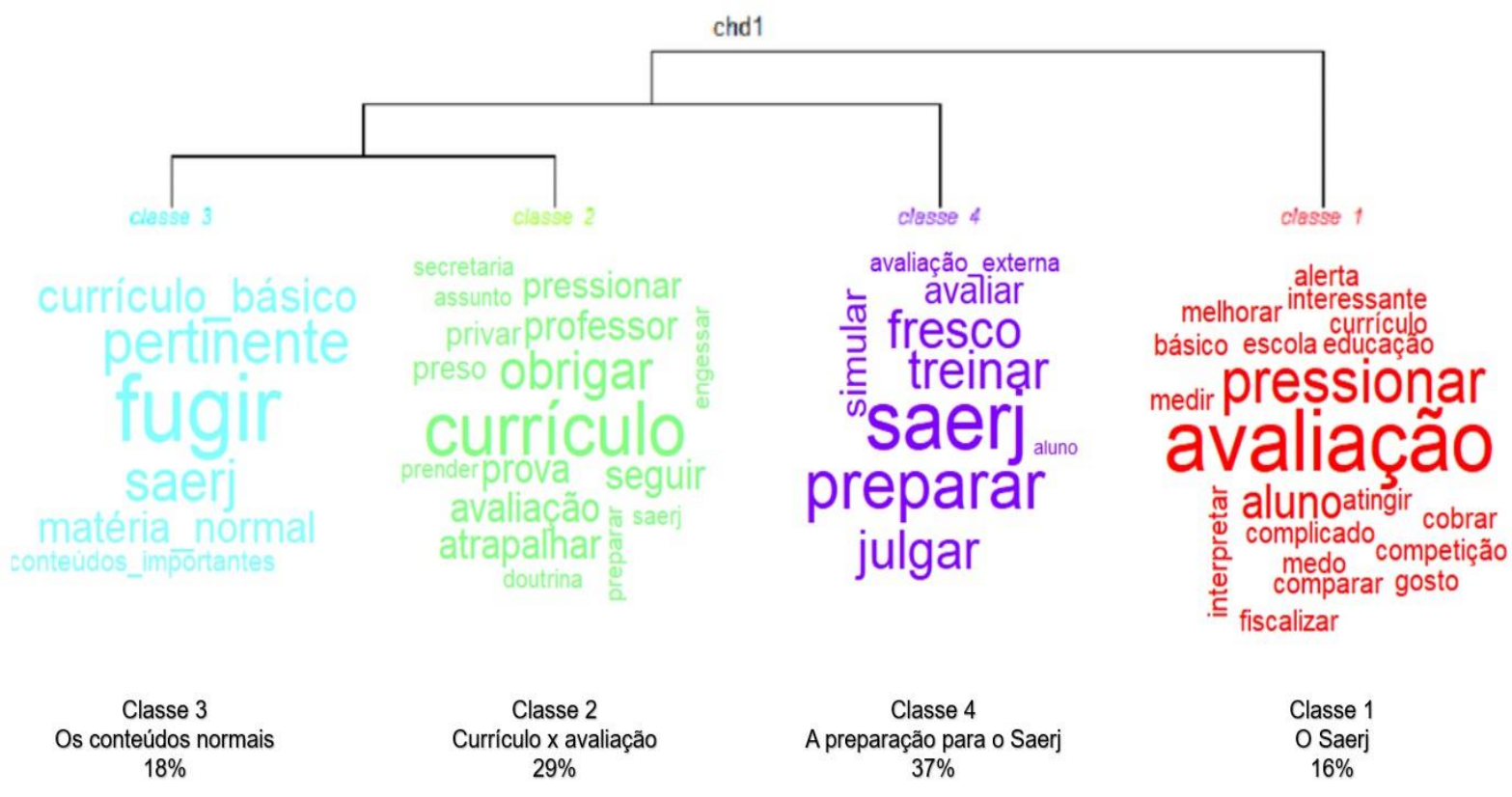

Fonte: autores.

\section{Resultados e discussão}

O programa identificou quatro classes que indicam os núcleos de sentido das representações discursivas dos participantes do estudo acerca da política educacional. Essas ideias centrais estão organizadas no tabela $1 \mathrm{com}$ suas respectivas frequências nos discursos dos professores.

Tabela 1 -

Ideias centrais identificadas nas representações discursivas dos professores da rede estadual de ensino acerca do Saerj 5 .

\begin{tabular}{c|c|c}
\hline Ideias centrais & Total de docentes & Frequência relativa \\
\hline O Saerj & 8 & $53 \%$ \\
\hline $\begin{array}{c}\text { A relação currículo- } \\
\text { avaliação }\end{array}$ & 12 & $80 \%$ \\
\hline Os conteúdos normais & 8 & $53 \%$ \\
\hline A preparação para o Saerj & 15 & $100 \%$ \\
\hline
\end{tabular}

Fonte: autores.

\footnotetext{
${ }^{4}$ No dendograma cada classe apresenta as palavras com maior frequência e proximidade de sentido no corpus textual produzido a partir das entrevistas com os quinze professores. As frequências são relativas ao volume dos segmentos de textos com escopo correspondente a cada classe e seu núcleo de sentido.

${ }^{5} \mathrm{Na}$ figura as frequências relativas não são cumulativas. Seus dados são referentes à porcentagem de participantes de estudo que apresentavam em seus discursos expressões-chave utilizadas na construção de cada discurso do sujeito coletivo - dsc.
}

Regae: Rev. Gest. Aval. Educ. $\quad$ Santa Maria

v. 9

ก. 18

Pub. contínua 2020

p. 1-17 
Os segmentos de texto dos discursos dos docentes categorizados pelo programa nos orientaram para especificarmos as ideias centrais acerca do Saerj, descritas no tabela 1. Com base nessas ideias centrais e nos segmentos de texto relativos a cada categoria destacada pelo software, produzimos os quatro dsc que traduzem as representações sociais dos participantes da pesquisa acerca do Saerj.

O dsc 1 apresenta as percepções dos professores em relação à avaliação externa. Naquele contexto, fazia oito anos que o Saerj estava presente no cotidiano das escolas estaduais.

Dsc 1: o Saerj

No começo, eu não tinha ideia do que iria acontecer quando disseram que ia ter essa avaliação. Fiquei muito confusa em relação a isso. Eu fico com medo porque as escolas são cobradas. É válido ter a avaliação externa, mas depende de como ela é interpretada. Você não pode comparar um aluno daqui, que vive num lugar complicado, com um aluno do interior do estado, de uma cidade pequena. Mas é interessante sim, como um alerta para o estado. Essas avaliações são boas, partindo do pressuposto de que eles querem melhorar a educação. Mas também é uma forma de medir se a gente tá dando o Currículo Básico, pra saber se ele tá sendo passado, meio que de fiscalizar o nosso trabalho. Eu não gosto dessa avaliação por causa das comparações, como se fosse uma competição pra atingir essas metas. Eu acho importante, mas poderia ser feito com menos pressão.

\section{frequência $53 \%$}

Uma das marcas evidenciadas neste projeto educacional foi a baixa margem de ambiguidade presente em seu desenho. O Saerj foi apresentado às escolas da rede com ampla divulgação por meio das mídias institucionais da Seeduc, desde sua primeira versão em 2008. Sua propagação nas escolas também era feita e acompanhada por agentes da Gestão Integrada da Escola, os quais também orientavam os gestores quanto a planos e metas a serem cumpridos no contexto da política educacional. Além disso, esses agentes também ofereciam suporte para direcionar o cumprimento da nova proposta curricular da rede estadual (Najjar, 2018).

Apesar de a política ter sido um empreendimento elaborado sem a participação dos gestores e professores da rede, suas diretrizes eram precisas. A Gide buscava clarificar seus objetivos e desmistificar as crenças em relação às avaliações externas e ao currículo (Rio de janeiro, 20113). Além disso, a política apostava em estratégias gerencialistas para impulsionar avanços na educação pública. Em seus arranjos estavam integradas avaliação, currículo, metas para melhorar os indicadores, bonificação salarial para os docentes e premiação para os estudantes com melhores desempenho no Saerj. 
Ao mesmo tempo a Seeduc oferecia formação continuada para os professores das disciplinas avaliadas e qualificação técnica para os gestores educacionais. Tudo isso com o objetivo de impulsionar a qualidade da educação pública estadual, a qual se revelava uma das mais baixas do país.

Desse modo o Saerj foi apresentado como uma avaliação cujo objetivo era "promover a análise do desempenho dos alunos da rede pública, proporcionando um retrato da rede, que pode e deve ser utilizado para que se repense as práticas pedagógicas" (Rio de janeiro, 2008, p 1). Vale salientar que as diretrizes utilizadas pela Seeduc para implantar o Saerj foram objetivas, no sentido de minimizar ambiguidades quanto aos fins de seu projeto de avaliação. Essa propriedade da política é abordada nas representações discursivas dos docentes, de acordo com o dsc 1: não havia problemas quanto o acompanhamento da qualidade da educação da rede pela Seeduc.

Contudo, no contexto dos agentes de linha de frente, há margem para conflitos em relação às marcas de accountability dessa política educacional, conforme o dsc 1 . Assim, nesse núcleo de sentido da representação, manifestam-se expressões que indicam algum grau de discordância por parte dos docentes quanto aos meios, especificamente no que diz respeito à pressão em relação às metas estabelecidas para cada escola avançar nos indicadores do Saerj e ao cumprimento da proposta curricular obrigatória.

Os posicionamentos dos docentes refletem as limitações encontradas na linha de frente da política e as pressões institucionais para sua implementação ao desempenharem suas funções junto aos alunos. Um desses pontos é o alinhamento da avaliação de monitoramento o e currículo básico da rede estadual, destacado no dsc 2 dos professores.

\section{Dsc 2: a relação currículo-avaliação}

Eu acho que essa avaliação externa atrapalha sim, já que eles te prendem ao Currículo Básico. E outra, a gente é obrigado a seguir o Currículo Básico porque temos que preparar o aluno pra essa avaliação externa. Essa prova engessou a gente! E aí eles acabam privando o professor de abrir um leque maior, de mostrar a ele um mundo de conhecimentos mais interessantes, porque você fica preso naquela doutrina ali, que eles acham que a gente tem que seguir. Mas o Saerj foi a única forma do professor trabalhar esses assuntos. Eles me obrigaram a trabalhar 0 Currículo Básico. Por esse motivo, eu me senti muito pressionada com a prova da Seeduc.

\section{frequência $80 \%$}

Elaborado com a participação de professores da rede estadual de educação selecionados por chamada pública nas mídias sociais da Seeduc, o currículo básico é descrito como "uma referência para todas as escolas estaduais" que objetiva o estabelecimento de uma "essência básica comum". Os documentos institucionais propõem "um conjunto seleto de conhecimentos essenciais", para a "compreensão das 
questões científicas, tecnológicas e humanas que permeiam a vida familiar, social e profissional" (Rio de Janeiro, 2012, p. 1).

Convergindo com as propostas curriculares contemporâneas, seu texto descreve habilidades e competências a serem desenvolvidas com os estudantes. Seus conteúdos oferecem mínimos comuns, elaborados para permitir que os docentes pudessem ir além da proposta universal da rede, comprometendo até $60 \%$ das aulas.

O dsc 2 descreve a estratégia da Seeduc de entrelaçar a avaliação de monitoramento e o currículo básico como um ponto sem ambiguidade para os professores: a proposta curricular obrigatória deve ser posta em prática, pois está vinculada ao Saerj. Entretanto, as representações sociais do sujeito coletivo são carregadas de significantes que traduzem dissentimentos em relação a esse instrumento de implantação: 'atrapalha', 'obrigado', 'engessou', 'preso', 'privando' e 'pressionado' são termos que revelam posicionamentos com certo grau de conflito na implementação da política.

Os sentidos das expressões utilizadas pelos professores em relação à vinculação do currículo básico e ao Saerj ficam mais evidenciados no dsc 3, de modo que os termos acerca dos conteúdos obrigatórios oficiais que objetivam trazer mais equidade à rede são ressignificados em meio aos instrumentos performativos da política. Essas expressões indicam a pouca receptividade dos docentes em relação aos conteúdos obrigatórios, os quais devem ser trabalhados para atender à avaliação externa, segundo o discurso do sujeito coletivo.

\section{Dsc 3: os conteúdos normais}

No início eu fugia do Currículo Básico, eu aplicava os conteúdos mais importantes! Eu só passei a trabalhar o currículo quando chegava a época do Saerj. Aí eu tenho que parar o meu conteúdo de nono ano e dar os assuntos do Currículo Básico por causa do Saerj. O Currículo Básico não trabalha aquilo que é pertinente ao nono ano. E depois que eu vejo que eles tão tranquilos com relação as coisas do Currículo Básico, dou a matéria normal. Eu não sei se ele foi feito para atender as necessidades do Saerj ou para atender as necessidades do aluno.

\section{frequência 53\%}

De acordo com o dsc 3 não há ambiguidade quanto à necessidade dos professores trabalharem o currículo oficial, pois os conteúdos do currículo básico foram pensados para serem um mínimo comum para todos os estudantes da rede. O currículo institucional obrigatório, entretanto, diverge da percepção dos professores sobre aquilo que consideram os conteúdos adequados para a série avaliada - nono ano. Eis um ponto de conflito, portanto, na política educacional (Mota; Lannes, 2017). 
Os docentes declaram trabalhar esses conteúdos para o Saerj, mas não os conceituam como os conteúdos mais importantes em sua prática. Considerando o grau de autonomia dos docentes, esse ponto é uma brecha para que tais agentes explorem seu poder de discricionaridade, diante da compulsoriedade de colocar em prática uma proposta distante de suas práticas pedagógicas.

Ao usar sua discricionariedade o sujeito coletivo trabalha os conteúdos institucionais que serão avaliados. No entanto, é preciso pausar os conteúdos normais para abordar os do Saerj, pois os alunos serão avaliados pela Seeduc. Nesse sentido, alguns autores têm destacado a necessidade de analisarmos os efeitos das políticas de responsabilização no cenário educacional. Sousa (2003), Esteban (2015) e Fetzner (2015) chamam a atenção para a possibilidade da ressignificação dos objetivos das avaliações ter efeitos indesejáveis, como o aprisionamento e o empobrecimento do currículo escolar.

Vale salientar que a política educacional da rede estadual do Rio de Janeiro (20082016) envolveu mecanismos com sólido potencial indutor de implementação. Os instrumentos de ação da política - como as metas, o currículo e as bonificações - são estratégias para regular os indicadores educacionais e demarcar a direção na qual se pretende avançar. Todavia, o cenário de implementação contemporâneo distancia-se das perspectivas weberianas das agências burocráticas. No nível de rua a política está sujeita a modificações: influenciada por questões contextuais ela é recriada e reinterpretada pelos agentes de linha de frente.

Nesse processo, diante da necessidade de materializar a proposta da rede estadual, os professores usam suas estratégias para concretizar a política. $\mathrm{O}$ dsc 4 , elaborado com expressões-chave encontradas nos depoimentos de todos os participantes do estudo, descreve outros aspectos de sua discricionariedade.

\section{Dsc 4: a preparação para o Saerj}

A partir do momento que tem uma avaliação externa, a gente trabalha o aluno pra que ele vá bem nessas avaliações. Até porque isso vai contar como nota para a escola. Eu usei um mês para preparar os meus alunos para a prova do Saerj, direcionando as aulas para o Currículo Básico. Eu deixo pra mais perto das avaliações do Saerj, pra ficar mais fresco. Eu peguei os Saerj dos anos anteriores pra tentar dar uma olhada, treinar os alunos, porque eles tinham que ir bem na prova. Eu parava o conteúdo normal pra poder prepará-los pro Saerj. Aqui a gente faz um simulado que segue esse modelo do Saerj e funciona como um bônus na nota. É behaviorismo, mas no final das contas eles serão julgados por isso.

frequência $100 \%$

O dsc 4 converge com aspectos evidenciados por outros pesquisadores que analisam as políticas de avaliação. Com isso, os reflexos das políticas de incentivo como o Saerj ganham saliência no currículo e nas práticas pedagógicas. Dessa maneira, na busca de melhorar os resultados dos indicadores educacionais, todos os docentes declararam treinar os seus alunos para a avaliação externa. Segundo a perspectiva dos 
docentes os instrumentos de implementação da política induzem os agentes de linha de frente a buscar melhores resultados, adotando estratégias de gaming com o objetivo de preparar os estudantes para os testes.

Para atender a essa demanda, na complexidade do cotidiano, os simulados são uma alternativa possível e legal nas brechas do Saerj, traduzindo outros aspectos da discricionariedade dos burocratas de nível de rua. Contudo, a centralidade das metas e indicadores, além de ser mais uma margem de conflito no cotidiano das escolas, também tem o potencial de aumentar a nebulosidade dos resultados das avaliações, cujo propósito é trazer um diagnóstico para orientar as tomadas de decisão. Sendo assim, o processo de implementação extrapola aquilo que foi definido nos textos.

\section{Considerações finais}

Os resultados da pesquisa, de acordo com a percepção dos agentes de linha de frente, indicam baixos níveis de ambiguidade quanto aos objetivos da política, porém considerável grau de conflito em relação aos meios e instrumentos de implementação. Nesta análise identificamos aspectos que aproximam seu modelo de uma implementação política, na perspectiva de Matland (1995).

Apesar da pouca ambiguidade presente na política educacional as estratégias gerencialistas utilizadas não contribuíram para minimizar a discricionariedade dos agentes de linha de frente, distanciando sua implementação dos objetivos iniciais e aumentando o grau de conflito entre os agentes de linha de frente. Nesse contexto, anunciado no discurso dos professores, havia resistências e insatisfações em relação às características do Saerj.

Os graus de ambiguidade e conflito, de acordo com as manifestações discursivas dos participantes do estudo, estão relacionados às variáveis descritas no quadro 1.

\section{Quadro 1 -}

Indicadores de ambiguidade e conflito quanto os meios e fins da política do Saerj na perspectiva dos participantes da pesquisa.

\begin{tabular}{|l|c|c|}
\hline \multicolumn{1}{|c|}{ Meios/fins } & Ambiguidade & Conflito \\
\hline Objetivos da política educacional & $\downarrow$ & $\downarrow$ \\
\hline Obrigatoriedade da proposta curricular & $\downarrow$ & $\uparrow$ \\
\hline Relação currículo versus avaliação externa & $\downarrow$ & $\uparrow$ \\
\hline $\begin{array}{l}\text { Cumprimento das metas dos indicadores } \\
\text { educacionais }\end{array}$ & $\downarrow$ & $\uparrow$ \\
\hline
\end{tabular}

Fonte: autores.

O grau de conflito quanto às características da política educacional, entre os agentes implementadores, foi um dos fatores que influenciou o início da greve dos professores em 2016, a qual se estendeu por cinco meses naquele ano. Embora os docentes não tenham conseguido avanços salariais ou o direito à carga horária de planejamento prevista em lei, o fim da política de accountability relacionada ao Saerj foi a principal reivindicação atendida na pauta dos professores. A grave crise financeira enfrentada pelo governo do Estado do Rio de Janeiro foi um fator decisivo quanto a esse ponto, pois a escassa disponibilidade de recursos limitou a capacidade de negociação da Seeduc junto aos 
docentes. Uma política de indução tem sua efetividade relacionada aos recursos investidos, portanto encerrou-se o ciclo de uma política, sob resistência e ampla insatisfação entre os burocratas de nível de rua.

No caso do Saerj a política foi desenhada com o objetivo de superar os resultados preocupantes das escolas estaduais revelados pelos indicadores educacionais. Contudo, apesar dos esforços, sua avaliação se traduz como exemplo de uma política que não conseguiu sustentar-se ao longo de seu percurso. Dessa maneira, o Estado perdeu um instrumento de coleta de dados, deixando de acompanhar os indicadores educacionais de suas escolas, fundamentais para a tomada de decisões no sentido de garantir avanços educacionais.

Esse impasse permaneceu até 2019, quando o Estado desenhou um novo modelo de avaliação com o objetivo de se distanciar das limitações experimentadas com essa política educacional. Para tanto, é fundamental considerar as possibilidades e limites diante do papel dos agentes de linha de frente nos processos de implementação. Especificamente no campo educacional, deve-se direcionar esforços para que a política seja compreendida, com seus objetivos acreditados, para que os investimentos dos recursos públicos sejam eficazes e promovam a diminuição das desigualdades educacionais.

\section{Referências}

BONAMINO, Alícia; SOUZA, Sandra Zákia. Três gerações de avaliação da educação básica no Brasil: interfaces com o currículo da/na escola. Educação e Pesquisa, São Paulo, v. 38, n. 2, 2012, p. 373-388.

BOURDIEU, Pierre. Structures, habitus, power: Basis for a theory of symbolic power. Culture/power/history: A reader in contemporary social theory, 1994, p. 155-199.

BRASIL. Índice de desenvolvimento da educação básica. Brasília: MEC, 2006.

BRASIL. Sinopses estatísticas da educação básica. Brasília: MEC, 2014.

BROOKE, Nigel. O futuro das políticas de responsabilização educacional no Brasil. Cadernos de Pesquisa, São Paulo, v. 36, n. 128, 2006, p. 377-401.

CAMARGO, Brígido Vizeu; JUSTO, Ana Maria. IRAMUTEQ: um software gratuito para análise de dados textuais. Temas em Psicologia, Ribeirão Preto, v. 21, n. 2, 2013, p. 513518.

ESTEBAN, Maria. Tereza; FETZNER, Andrea. A redução da escola: a avaliação externa e o aprisionamento curricular. Educar em Revista, Curitiba: 2015, p. 75-92.

FLICK, Uwe. Introdução à pesquisa qualitativa. Porto Alegre: Artmed, 2008.

HILL, Michael; HUPE, Peter. The multi-layer problem in implementation research. Public Management Review, London, 2003, p. 471-490.

LEFÈVRE, Fernando; LEFÈVRE, Ana. O sujeito coletivo que fala o que fala. InterfaceComunic, Saúde, Educ, Botucatu, v. 10, n. 20, 2006, p. 517-524.

LEFÈVRE, Fernando. Discurso do sujeito coletivo, complexidade e auto-organização. Ciências e Saúde Coletiva, Rio de Janeiro, v. 14, n. 4, 2009, p. 93-120. 
LEFÈVRE, Fernando. Discurso do sujeito coletivo: representações sociais e intervenções comunicativas. Texto \& Contexto Enfermagem, Santa Catarina, v. 23, n. 2, 2014 p. 502507.

LIPSKY, Michael. Street-level bureaucracy: dilemmas of the individual in public services. Nova York: Russel Sage Foundation, 1980.

LOTTA, Gabriela S. Implementação de políticas públicas: o impacto dos fatores relacionais e organizacionais sobre a atuação dos burocratas de nível de rua no Programa Saúde da Família. São Paulo: USP, 2010. 295f. Tese (doutorado em Ciências Políticas). Universidade de São Paulo.

LOTTA, Gabriela S. O papel das burocracias do nível da rua na implementação de políticas públicas: entre o controle e a discricionariedade. In: FARIA, Carlos Aurélio Pimenta de (org.). Implementação de políticas públicas: teoria e prática. Belo Horizonte: PUCMinas, 2012, p. 20-49.

MACHADO, Cristiane; ALAVARSE, Ocimar M; ARCAS, Paulo Henrique. Sistemas estaduais de avaliação: interfaces com qualidade e gestão da educação. Revista Brasileira de Política e Administração da Educação, Rio de Janeiro, v. 31, n. 3, 2015, p. 667-680.

MATLAND, Richard. Synthesizing the implementation literature: the ambiguity-conflict model of policy implementation. Journal of Public Administration Research and Theory, Lawrence, v. 5, n. 2, abr. 1995, p. 145-174.

MOSCOVICl, Serge. Representações sociais: investigações em psicologia social. Petrópolis: Vozes, 2007, p. 404.

MOSCOVICl, Serge. A psicanálise, sua imagem e seu público. Petrópolis: Vozes, 2012.

MOTA, Diego; LANNES, Denise Rocha Correa. A centralidade das representações sociais de um currículo de habilidades entre professores. Revista Espaço do Currículo, João Pessoa, v. 10, n. 3, 2017, p. 429-447.

NAJJAR, Jorge. A gestão da educação fluminense $e$ as implicações do modelo gerencialista. Revista online de Política e Gestão Educacional, Araraquara, v. 22, 2018, p. 49-66.

REINERT, Max. Classification descendante hierarchique et analvse lexicale par contexteapplication au corpus des poesies D'A. Rihbaud. Bulletin of Sociological

Methodology/Bulletin de Méthodologie Sociologique, Paris, 1987, p. 53-90.

RIO DE JANEIRO. O Saerj: apresentação, 2008. Caed-Ufjf. Disponível em http://www.avaliacaoexternasaerj.caedufjf.net/matriz-de-referencia/. Acesso em 26 nov. 2019.

RIO DE JANEIRO. Melhores alunos da rede são premiados com notebooks, 2011. Disponível em: http://www.avaliacaoexternasaerj.caedufjf.net/. Acesso em 03/11/2019.

RIO DE JANEIRO. Planejamento estratégico da Seeduc, 2011. Disponível em: http://www.avaliacaoexternasaerj.caedufjf.net/. Acesso em 03/11/2019.

RIO DE JANEIRO. Gestão integrada da escola, 2011. Disponível em: http://download.rj.gov.br/documentos/10112/553225/DLFE37306.pdf/InformativoGIDE.pdf. Acesso em 7 nov. 2019.

RIO DE JANEIRO; Currículo mínimo, 2012. Disponível em http://www.rj.gov.br/web/seeduc/exibeconteudo?article-id=759820. Acesso em 11 out. 2019. 
RIO DE JANEIRO. Revista do Sistema de Avaliação - Saerj 2016. Disponível em http://www.avaliacaoexternaSaerj.caedufjf.net/wp-content/uploads/2016/04/RJ-SAERJ2015-RS-RE_WEB.pdf. Acesso em 11 out. 2019.

RIO DE JANEIRO. Últimas avaliações de 2015 do sistema estadual são aplicadas, 2016. Disponível em http://www.avaliacaoexternasaerj.caedufjf.net/2015/11/24/ultimasavaliacoes-de-2015-do-sistema-estadual-sao-aplicadas/. Acesso em 4 dez. 2019.

SOUSA, Sandra Zákia. Possíveis impactos das políticas de avaliação no currículo escolar. Cadernos de Pesquisa, São Paulo, n. 119, 2003, p. 175-190.

SOUSA, Sandra Zákia. Concepções de qualidade da educação básica forjadas por meio de avaliações em larga escala. Avaliação: Revista da Avaliação da Educação Superior, Campinas, 2014, p. 407-420.

Diego Mota é professor no Colégio Pedro II é estudante no curso de doutorado em Educação na Pontifícia Universidade Católica do Rio de Janeiro.

Orcid: https://orcid.org/0000-0001-5279-8630.

Endereço: Rua Humaitá, 80 - 22261-001 - Rio de Janeiro - RJ - Brasil.

E-mail: diegoomota@gmail.com.

Maria Océlia Mota é doutora em Educação e pesquisadora no Laboratório de Avaliação da Educação da Pontifícia Universidade Católica do Rio de Janeiro. Orcid: https://orcid.org/0000-0002-3927-6261.

Endereço: Rua Marquês de São Vicente, 225 - 22451-900 - Rio de Janeiro - RJ Brasil. E-mail: oceliamota@gmail.com.

Recebido em 7 de fevereiro de 2020.

Aceito em 24 de abril de 2020.

(c) (1) 